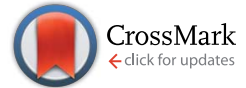

Cite this: Chem. Sci., 2015, 6, 3236

\title{
Very bright mechanoluminescence and remarkable mechanochromism using a tetraphenylethene derivative with aggregation-induced emission $\uparrow$
}

\author{
Bingjia Xu, $\neq^{\text {ab }}$ Jiajun He, $\star^{a}$ Yingxiao $M u,{ }^{a}$ Qiangzhong Zhu, ${ }^{b}$ Sikai Wu, ${ }^{a}$ Yifan Wang, ${ }^{c}$ \\ Yi Zhang, ${ }^{* a}$ Chongjun Jin, ${ }^{b}$ Changcheng Lo, ${ }^{c}$ Zhenguo Chi, ${ }^{* a}$ Alan Lien, ${ }^{d}$ Siwei Liu ${ }^{a}$ \\ and Jiarui $\mathrm{Xu}^{\star a}$
}

Organic materials exhibiting mechanoluminescence $(\mathrm{ML})$ are promising for usage in displays, lighting and sensing. However, the mechanism for $M L$ generation remains unclear, and the light-emitting performance of organic ML materials in the solid state has been severely limited by an aggregationcaused quenching (ACQ) effect. Herein, we present two strongly photoluminescent polymorphs (i.e., $C_{g}$ and $C_{b}$ ) with distinctly different $M L$ activities based on a tetraphenylethene derivative $P_{4} T A$. As an aggregation-induced emission (AIE) emitter, $P_{4} T A$ perfectly surmounted the $A C Q$, making the resultant block-like crystals in the $C_{g}$ phase exhibit brilliant green $M L$ under daylight at room temperature. The $M L$-inactive prism-like crystals $C_{b}$ can also have their $M L$ turned on by transitioning toward $C_{g}$ with the aid of dichloromethane vapor. Moreover, the $C_{g}$ polymorph shows $M L$ and mechanochromism simultaneously and respectively without and with UV irradiation under a force stimulus, thus suggesting a feasible design direction for the development of efficient and multifunctional ML materials.

Received 7th February 2015
Accepted 16th March 2015
DOI: $10.1039 /$ c5sc00466g
www.rsc.org/chemicalscience

\section{Introduction}

The mechanoluminescence (ML) phenomenon was first found by Francis Bacon in $1605 .{ }^{1}$ Heretofore, research on exploiting advanced ML materials has not yet been a major focus. ${ }^{2}$ Materials with brilliant $\mathrm{ML}$ are actually of great importance from both fundamental and practical viewpoints because they are promising for usage in displays, as well as light sources and sensors. ${ }^{2,3}$ However, a comprehensive understanding of the crystal properties required for ML activity and the corresponding mechanisms is less well demonstrated. ${ }^{4}$ This lack in understanding leads to feasible design principles for these emitters, particularly those with satisfactory ML brightness,

${ }^{a}$ PCFM Lab, GD HPPC Lab, Guangdong Engineering Technology Research Center for High-performance Organic and Polymer Photoelectric Functional Films, State Key Laboratory of Opto-electronic Material and Technologies, School of Chemistry and Chemical Engineering, Sun Yet-sen University, Guangzhou 510275, China. E-mail: ceszy@mail.sysu.edu.cn; chizhg@mail.sysu.edu.cn; xjr@mail.sysu.edu.cn; Fax: +86 20 84112222; Tel: +862084112712

${ }^{b}$ State Key Laboratory of Optoelectronic Material and Technologies, School of Physics and Engineering, Sun Yat-sen University, Guangzhou 510275, China

'Shenzhen China Star Optoelectronics Technology Co., Ltd, Guangdong, China

${ }^{d}$ TCL Corporate Research, Guangdong, China

$\dagger$ Electronic supplementary information (ESI) available: Details of the synthesis; structural information for the compound (NMR, IR, and mass spectra); Tables S1-S5; Fig. S1-S11. CCDC 1037840 and 1057432. For ESI and crystallographic data in CIF or other electronic format see DOI: $10.1039 / \mathrm{c} 5 \mathrm{sc00466g}$

\$ These authors contributed equally to the preparation of this work. being rarely found. ${ }^{5}$ As reported previously, the performance of organic ML compounds can be related to both their molecular and molecular-assembly structures. ${ }^{6}$ Therefore, controlling the molecular arrangements in the solid state and achieving a molecular-level understanding of the relationship between the molecular conformations and packing characteristics and the resulting optical properties are the essential issues in obtaining efficient ML materials.

Notably, non-covalent intermolecular interactions, such as $\pi-\pi$ stacking and hydrogen bonding, are important in constructing the supramolecular systems. ${ }^{7}$ These interactions are able to influence the final packing structure strongly, thereby making polymorphism with different ML activities more probable. ${ }^{6 a, 8}$ Nevertheless, in most cases, typical $\pi-\pi$ stacking interactions often lead to aggregation-caused quenching, which poses significant difficulties for development of high-performance ML materials. ${ }^{4 b, 9}$ By contrast, a diametrically opposed effect was recently found to be operative in a class of chromophores with twisted conformations (e.g., tetraphenylethene derivatives), which exhibit enhanced emission in the solid state with respect to the fluid solution. ${ }^{\mathbf{1 0}}$ The discovery of this abnormal phenomenon, known as aggregation-induced emission (AIE), has sparked a rapid expansion in the field of photoluminescent sensors and electroluminescent devices. ${ }^{\mathbf{1 1}}$ AIE also provides new possibilities for designing highly mechanoluminescent materials.

This study presents a new polymorphic system that can be facilely and controllably constructed using a tetraphenylethene 
derivative [i.e., 5-(4-(1,2,2-triphenylvinyl)phenyl)thiophene-2carbaldehyde $\left.\left(\mathrm{P}_{4} \mathrm{TA}\right)\right]$ as the building block (Fig. 1). The two crystalline polymorphs of $\mathrm{P}_{4}$ TA show strong blue- and greencolored photoluminescence (PL). The blue-light crystals are significantly ML inactive, whereas the green-light ones are highly mechanoluminescent because of their distinctly different molecular packing mode and unique AIE character. The existence of polymorphs from the same molecule with exactly opposite properties provides a unique prototype to investigate the crystalline structures required for ML activity and the effect of AIE properties on ML enhancement. The relationship between the ML and the mechanofluorochromism of $\mathrm{P}_{4} \mathrm{TA}$ is also presented.

\section{Results and discussion}

$\mathrm{P}_{4} \mathrm{TA}$ was straightforwardly prepared through a palladiumcatalyzed coupling reaction by introducing 2-thiophenaldehyde to the tetraphenylethene moiety (Scheme S1 $\dagger$ ). The purified material was then characterized using nuclear magnetic resonance (NMR) spectroscopy and X-ray crystallography. The satisfactory data obtained fully confirmed its expected molecular structure (ESI $\dagger$ ).

The UV-visible absorption spectrum of $\mathrm{P}_{4} \mathrm{TA}$ was measured in a dichloromethane (DCM) solution. Two absorption bands centered at 317 and $366 \mathrm{~nm}$ were observed. These two bands were associated with the $\pi-\pi^{*}$ transition and intramolecular charge transfer, respectively (Fig. S1†). The large Stokes shift $\left(68027 \mathrm{~cm}^{-1}\right.$ ) between the absorption and fluorescence spectra $\left(\lambda_{\mathrm{em}, \max }=513 \mathrm{~nm}\right)$ of $\mathrm{P}_{4} \mathrm{TA}$ in DCM was indicative of the structural difference between the ground and excited states. The resulting $\mathrm{P}_{4}$ TA compound would probably also be AIE-active on considering that tetraphenylethene is the most frequently used AIE unit. To confirm this probability, a tetrahydrofuran (THF) solution of $\mathrm{P}_{4}$ TA was titrated with water and the change in the fluorescence emission was monitored. $\mathrm{P}_{4} \mathrm{TA}$ exhibited an extremely weak emission in the THF solution, where it was well dissolved (Fig. 2a). Hence, almost no PL signal was recorded. However, when $90 \%(\mathrm{v} / \mathrm{v})$ water was present, a strong green emission that peaked at $499 \mathrm{~nm}$ was observed and the corresponding intensity ( $\sim 705$ a. u.) dramatically increased by up to $\sim 100$ times compared to that at the $0 \%$ water fraction ( $\sim 7$ a. u.). Adding water to the THF solution of $\mathrm{P}_{4}$ TA significantly induced the formation of nanoparticles because $\mathrm{P}_{4} \mathrm{TA}$ molecules contain highly hydrophobic aromatic rings. In other words, the emission enhancement was caused by molecule aggregation which suggests that $\mathrm{P}_{4} \mathrm{TA}$ is AIE-active. ${ }^{12}$

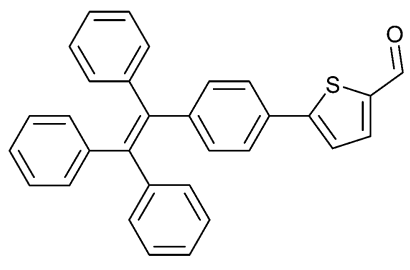

Fig. 1 Molecular structure of $\mathrm{P}_{4} \mathrm{TA}$.
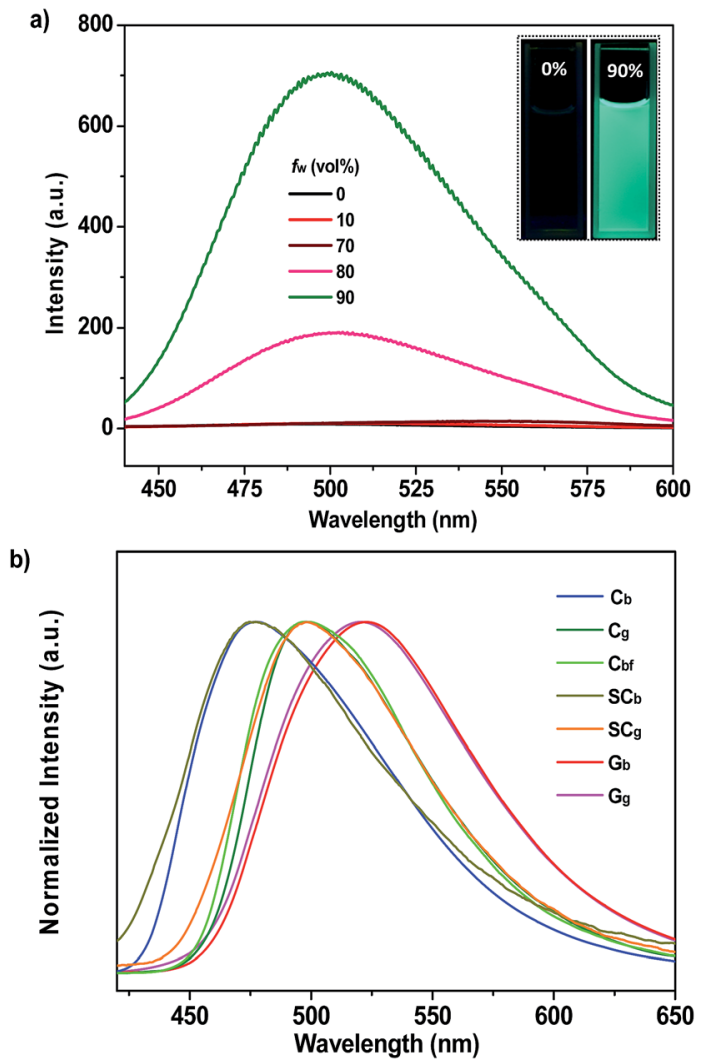

Fig. 2 (a) PL spectra of dilute solutions of $\mathrm{P}_{4} \mathrm{TA}$ in water-THF mixtures with different water fractions $\left(f_{\mathrm{w}}\right)$. The inset depicts the emission images of the compound in pure THF and in the $90 \%$ water fraction mixture under $365 \mathrm{~nm}$ UV illumination $(10 \mu \mathrm{M})$. (b) PL spectra of $\mathrm{P}_{4}$ TA in different phases.

The prominent AIE character of $\mathrm{P}_{4}$ TA motivated the application of the material in the solid state. Accordingly, block-like crystals ( $\mathrm{C}_{\mathrm{g}}$-form) were achieved through solvent evaporation of $\mathrm{P}_{4} \mathrm{TA}$ in a mixed solvent of $n$-hexane and DCM (Fig. S2a †). Compared to the emissive nanoaggregates in $\mathrm{THF}-\mathrm{H}_{2} \mathrm{O}$, the asprepared sample $\mathrm{C}_{\mathrm{g}}$ exhibited an even stronger green-light emission, centered at $498 \mathrm{~nm}\left[\Phi_{\mathrm{F}, \mathrm{s}}=52 \%\right]$ (Fig. 2b). By grinding the $\mathrm{C}_{\mathrm{g}}$ crystals with a pestle or shearing them with a spatula, a very bright green light emission peaking at $517 \mathrm{~nm}$ was observed in the dark without UV irradiation (Fig. 3a and c and Video $\mathrm{S} 1 \dagger$ ). This experiment unambiguously illustrated that $\mathrm{P}_{4} \mathrm{TA}$ in the $\mathrm{C}_{\mathrm{g}}$-form was ML-active. The strong ML of $\mathrm{C}_{\mathrm{g}}$ was indeed clearly seen even under daylight at room temperature and was maintained while the crystals were crushed (Fig. 3c and Video S2 $\dagger$ ). Certain organic materials, such as coumarin, phenanthrene, $N$-acetyl anthranilic acid, $N$-isopropyl carbazole and $N$-phenyl imides, have also been reported to show mechanoluminescence activities. However, none of these materials could emit a ML strong enough to be observed with the naked eye under daylight at room temperature., ${ }^{5,13}$ The poor performance of the conventional organic ML materials should be attributed to their intrinsic ACQ property, which leads to the low emitting efficiency in the solid state. By contrast, the unique AIE feature of $\mathrm{P}_{4}$ TA perfectly surmounted the ACQ effect and 

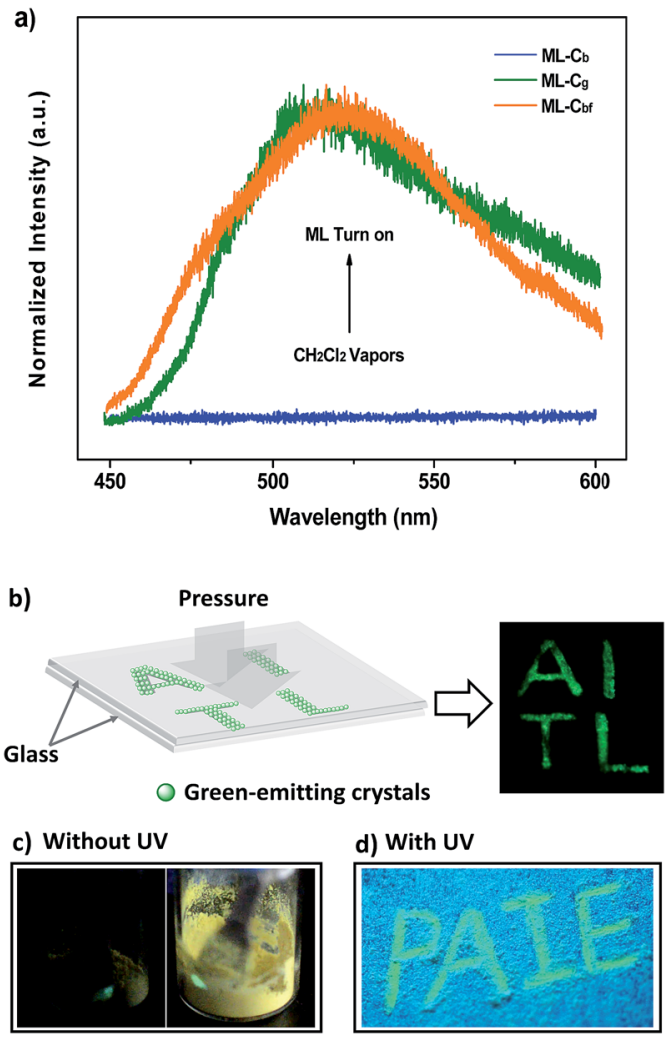

Fig. 3 (a) ML spectra of $P_{4} T A$ in different phases. (b) An image of the capital letters 'AITL' being shown through ML of $P_{4} T A$ in the dark under a pressure stimulus at room temperature. (c) ML images of $P_{4} T A$ in the dark (left) and under daylight (right) at room temperature. (d) The writable mechanochromic fluorescence of $\mathrm{P}_{4} \mathrm{TA}$, demonstrated using the capital letters 'PAIE', generated with a metal rod.

exhibited a positive effect on luminescence enhancement, thereby giving the brilliant $\mathrm{ML}$ of $\mathrm{C}_{\mathrm{g}}$. To further demonstrate the ML characteristics of $\mathrm{C}_{\mathrm{g}}$, a simple device was made by sandwiching the sample between two pieces of pre-sculptured glass. The capital letters 'AITL' were clearly displayed when pressure was used as the driving force, which suggests the ML 'display capability' of $\mathrm{C}_{\mathrm{g}}$ (Fig. $3 \mathrm{~b}$ ). As such, the extraordinary AIE-active ML material $\mathrm{P}_{4} \mathrm{TA}$ will be a promising candidate for displays and optical recording.

Interestingly, another type of prism-like crystal $\left(\mathrm{C}_{\mathrm{b}}\right.$-form) was observed while exploring different processing conditions. The $\mathrm{C}_{\mathrm{b}}$-form crystals, which showed an intense blue-light emission that peaked at $476 \mathrm{~nm}\left(\Phi_{\mathrm{F}, \mathrm{s}}=36 \%\right)$, could be obtained by adding ethanol into a $\mathrm{P}_{4} \mathrm{TA} / \mathrm{DCM}$ solution under the action of ultrasound (Fig. S2b $\dagger$ ). However, in contrast to the vivid $\mathrm{C}_{\mathrm{g}}$ phenomenon, the $\mathrm{P}_{4}$ TA sample completely lost its ML activity when aggregated in the $\mathrm{C}_{\mathrm{b}}$-form (Fig. 3a). The $\mathrm{C}_{\mathrm{b}}$ crystals showed a small melting endothermic shoulder peak at $191{ }^{\circ} \mathrm{C}$ and a sharp peak at $198{ }^{\circ} \mathrm{C}$ in the first heating curve of differential scanning calorimetry (DSC) (Fig. 4a), indicating that $\mathrm{C}_{\mathrm{b}}$ was mainly composed of microcrystals that melt at $198^{\circ} \mathrm{C}$. This result is different from that of $\mathrm{C}_{\mathrm{g}}$, which melts at $206{ }^{\circ} \mathrm{C}$. Moreover, the powder X-ray diffraction (XRD) spectra also exhibited distinctly different patterns for the two samples
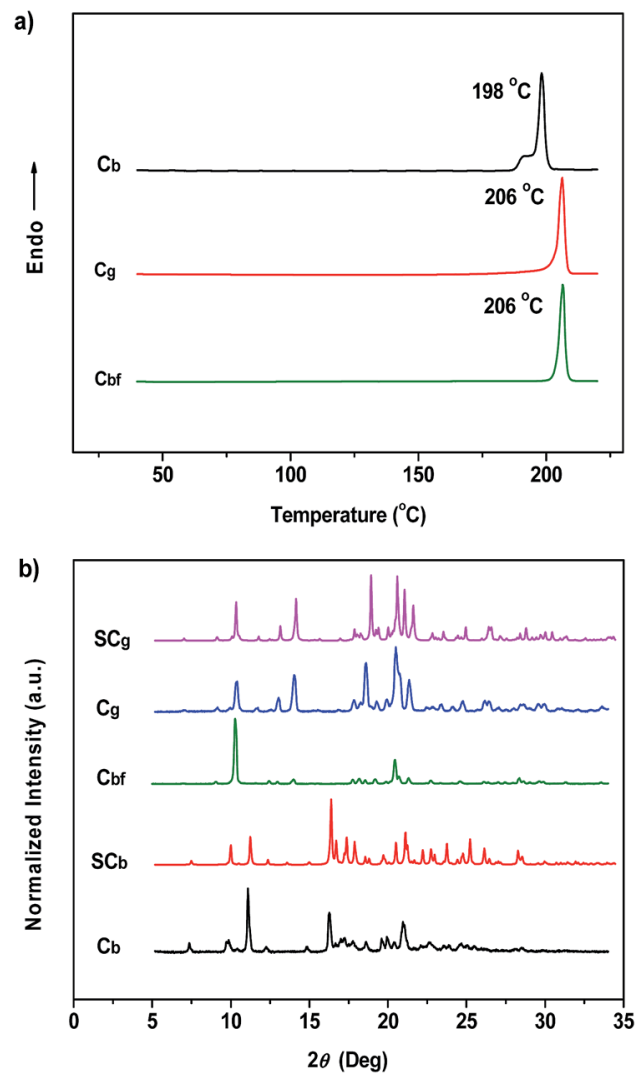

Fig. 4 DSC curves (a) and XRD patterns (b) of $\mathrm{P}_{4} \mathrm{TA}$ in different phases.

(Fig. 4b). These results imply that the different ML activities of $\mathrm{C}_{\mathrm{g}}$ and $\mathrm{C}_{\mathrm{b}}$ could be attributed to their dissimilar molecular packing modes. A single crystal X-ray analysis was thus performed for the $\mathrm{P}_{4}$ TA crystals to obtain more insight into this aspect. Single crystals of the two polymorphs (i.e., $\mathrm{SC}_{\mathrm{g}}$ and $\mathrm{SC}_{\mathrm{b}}$ ) suitable for X-ray structural analysis were isolated through slow solvent evaporation of $\mathrm{P}_{4}$ TA in mixtures of ethanol and $\mathrm{CHCl}_{3}$ of different concentrations.

The $\mathrm{SC}_{\mathrm{g}}$ and $\mathrm{SC}_{\mathrm{b}}$ samples emitted intense green or blue light peaked at 499 and $476 \mathrm{~nm}$, respectively (Fig. 2b and 5a and $b$ ). These light emissions are similar to those of the asprepared crystals of $\mathrm{C}_{\mathrm{g}}$ and $\mathrm{C}_{\mathrm{b}}$. The main peaks of the simulated XRD patterns of $\mathrm{SC}_{\mathrm{g}}$ and $\mathrm{SC}_{\mathrm{b}}$ also agree well with those in the patterns obtained from $\mathrm{P}_{4} \mathrm{TA}$ in the $\mathrm{C}_{\mathrm{g}}$ and $\mathrm{C}_{\mathrm{b}}$ phases, which suggests that the initial powders were mainly composed of $\mathrm{P}_{4} \mathrm{TA}$ microcrystals in the polymorphs of $\mathrm{SC}_{\mathrm{g}}$ and $\mathrm{SC}_{\mathrm{b}}$ (Fig. 4b). Further systematic analysis revealed that both $\mathrm{SC}_{\mathrm{g}}$ and $\mathrm{SC}_{\mathrm{b}}$ belong to the non-centrosymmetric polar space group of $P(2) 1$ (Table $\mathrm{S} 1 \dagger$ ). Some previous reports have shown that dipolar structures and non-centrosymmetric molecular arrangements are favorable for obtaining piezoelectric properties, which were closely pertinent to the ML activities of the crystals. ${ }^{14}$ In principle, the fracture of crystals with a strong piezoelectric effect will lead to electronic discharge at the crack surface, which would result in dye excitation and generation of ML for the crystals. ${ }^{5,15}$ The molecular structure of $\mathrm{P}_{4} \mathrm{TA}$ and the crystalline symmetry of $\mathrm{SC}_{\mathrm{g}}$ and $\mathrm{SC}_{\mathrm{b}}$ also meet 

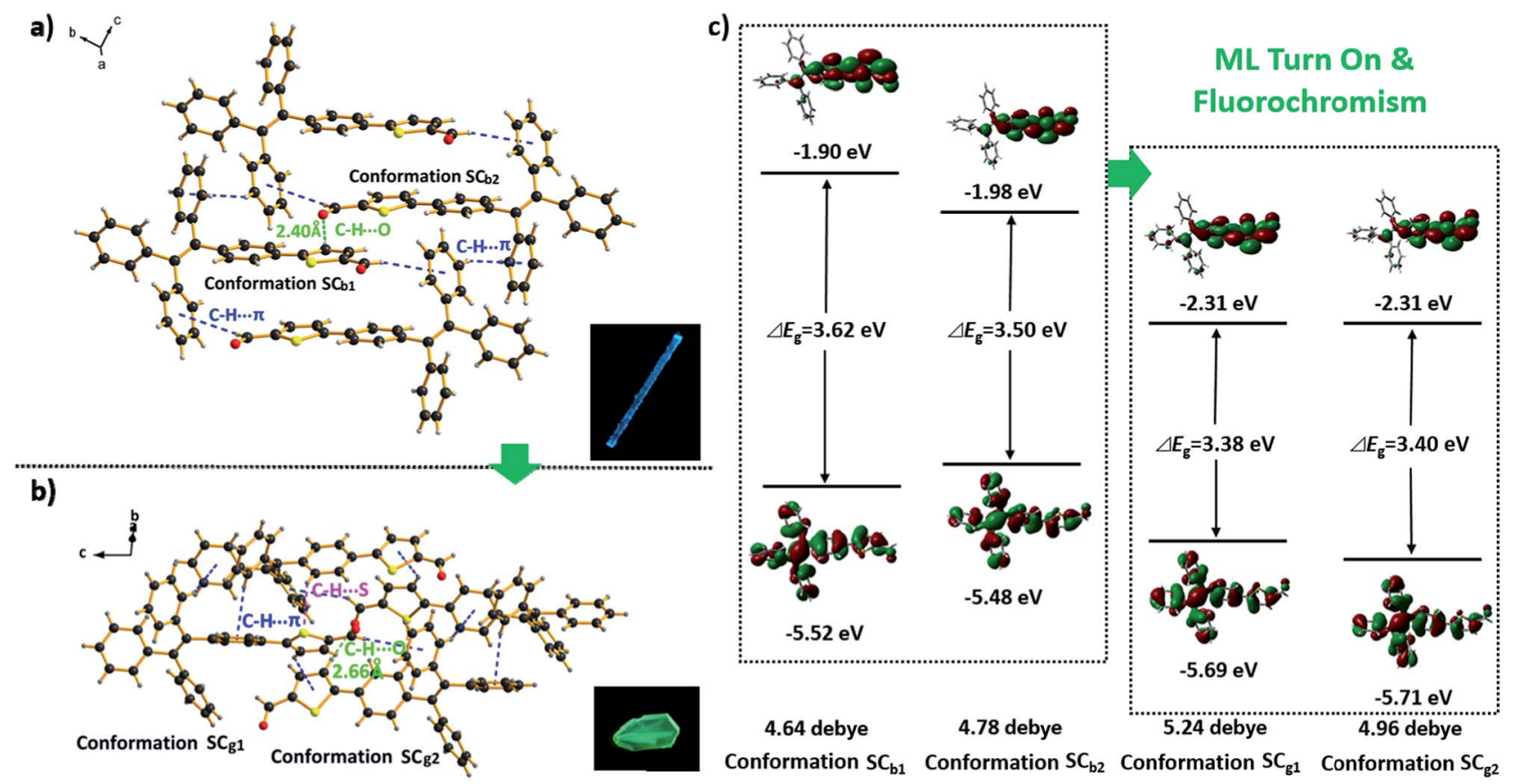

Fig. 5 Stacking modes and intermolecular interactions of the molecules in polymorphs $\mathrm{SC}_{b}(\mathrm{a})$ and $\mathrm{SC}_{\mathrm{g}}$ (b); the insets show the fluorescence images of $\mathrm{SC}_{\mathrm{b}}$ and $\mathrm{SC}_{\mathrm{g}}$ under an excitation of $365 \mathrm{~nm}$ UV light. (c) The HOMO (lower images) and LUMO (upper images) of the four conformations of $\mathrm{P}_{4} T A$ in polymorphs $\mathrm{SC}_{b}$ and $\mathrm{SC}_{\mathrm{g}}$ calculated at the B3LYP/6-31G(d, p) level.

the requirements for piezoelectric properties, thus making the as-prepared crystals of $\mathrm{C}_{\mathrm{g}}$ and $\mathrm{C}_{\mathrm{b}}$ more active and more likely to achieve the ML character. However, the dipole moments and the HOMO-LUMO band gaps $\left(\Delta E_{\mathrm{g}}\right)$ of the molecules in the $\mathrm{SC}_{\mathrm{g}}$ and $\mathrm{SC}_{\mathrm{b}}$ polymorphs were different. These differences were caused by their distinct molecular conformations and packing characteristics. The asymmetric units in both polymorphs (i.e., $\mathrm{SC}_{\mathrm{g}}$ and $\mathrm{SC}_{\mathrm{b}}$ ) were composed of two crystallographically independent molecules (i.e., $\mathrm{SC}_{\mathrm{g} 1}$ and $\mathrm{SC}_{\mathrm{g} 2}$ for $\mathrm{SC}_{\mathrm{g}}$, and $\mathrm{SC}_{\mathrm{b} 1}$ and $\mathrm{SC}_{\mathrm{b} 2}$ for $\mathrm{SC}_{\mathrm{b}}$ ). Each molecule showed the formation of a $\mathrm{C}-\mathrm{H} \cdots \mathrm{O}$ intermolecular hydrogen bond (Fig. $5 \mathrm{a}$ and $\mathrm{b}, \mathrm{S} 3$ and $\mathrm{S} 4 \uparrow$ ). Compared with $\mathrm{SC}_{\mathrm{b}}$, the most notable conformational difference of $\mathrm{P}_{4} \mathrm{TA}$ in the $\mathrm{SC}_{g}$ polymorph was the dihedral angle $\theta$ between the thiophene and the adjacent phenyl ring. While the conformations of $\mathrm{P}_{4} \mathrm{TA}$ were twisted $\theta$ $=18.9^{\circ}$ for $\mathrm{SC}_{\mathrm{g} 1}$ and $6.1^{\circ}$ for $\mathrm{SC}_{g_{2}}$ ) in polymorph $\mathrm{SC}_{g}$, the two aromatic rings were nearly coplanar in polymorph $\mathrm{SC}_{\mathrm{b}}(\theta=$ $2.5^{\circ}$ for $\mathrm{SC}_{\mathrm{b} 1}$ and $4.7^{\circ}$ for $\mathrm{SC}_{\mathrm{b} 2}$ ) (Table $\mathrm{S} 2 \dagger$ ). In the case of $\mathrm{SC}_{\mathrm{g}}$, the two thiophene rings of $\mathrm{SC}_{\mathrm{g} 1}$ and $\mathrm{SC}_{\mathrm{g} 2}$ were almost perpendicular to each other, showing a dihedral angel of $85.8^{\circ}$. By contrast, an anti-parallel packing mode was observed between the thiophene rings of $\mathrm{SC}_{\mathrm{b} 1}$ and $\mathrm{SC}_{\mathrm{b} 2}\left(\theta=3.7^{\circ}\right)$ in $\mathrm{SC}_{\mathrm{b}}$.

The most popular B3LYP density functional theory was then used to calculate the dipole moments and the $\Delta E_{\mathrm{g}}$ of $\mathrm{P}_{4} \mathrm{TA}$ in the four conformations at the $6-31 \mathrm{G}(\mathrm{d}, \mathrm{p})$ level based on their ground state geometries in the single crystals. Fig. $5 \mathrm{c}$ presents the results. The dipole moments of $\mathrm{SC}_{\mathrm{g} 1}$ and $\mathrm{SC}_{\mathrm{g} 2}$ in the $\mathrm{SC}_{\mathrm{g}}$ polymorph were 5.24 and 4.96 debye (D), respectively. Both values were larger than those of $\mathrm{SC}_{\mathrm{b} 1}(4.64 \mathrm{D})$ and $\mathrm{SC}_{\mathrm{b} 2}(4.78 \mathrm{D})$ in $\mathrm{SC}_{\mathrm{b}}$. The larger dipole moments of the molecules combining the non-centrosymmetric molecular arrangement may result in a larger net-dipole moment of the crystalline structure, and would subsequently lead to a stronger piezoelectric effect in the $\mathrm{SC}_{g}$ polymorph when breaking the crystals. The theoretical calculation results also suggest that the molecules in both $\mathrm{SC}_{g}$ and $\mathrm{SC}_{\mathrm{b}}$ have ICT characteristics: the electronic transitions (mainly from HOMO to LUMO for all the four conformations in $\mathrm{SC}_{\mathrm{g}}$ and $\mathrm{SC}_{\mathrm{b}}$ ) from the occupied orbitals delocalized over the TPE (donor) moiety to the thiophenaldehyde (acceptor) moiety made major contributions to the excited states (Fig. 5c and Table $\mathrm{S} 4 \dagger) \cdot{ }^{16} \mathrm{SC}_{\mathrm{g} 1}$ and $\mathrm{SC}_{\mathrm{g} 2}$ showed even smaller $\Delta E_{\mathrm{g}}(\mathrm{HOMO} \rightarrow$ LUMO) values of 3.38 and $3.40 \mathrm{eV}$, respectively, as compared to those of $\mathrm{SC}_{\mathrm{b} 1}(3.62 \mathrm{eV})$ and $\mathrm{SC}_{\mathrm{b} 2}(3.50 \mathrm{eV})$ in the $\mathrm{SC}_{\mathrm{b}}$ polymorph. The calculations showed good agreement with the solid state UV-visible spectra of $\mathrm{C}_{\mathrm{g}}$ and $\mathrm{C}_{\mathrm{b}}$, which absorbed at $373 \mathrm{~nm}$ and $367 \mathrm{~nm}$, respectively (Fig. S5†). The preceding results thus indicate that the electrons of the molecules in $\mathrm{SC}_{g}$ can be excited with a lower energy. Hence, the stronger piezoelectric effect and the lower electronic transition energy resulted in the excitation of $\mathrm{P}_{4}$ TA molecules and the generation of ML in the $\mathrm{SC}_{\mathrm{g}}$ phase by breaking the crystals. Meanwhile, all the molecules adopted a highly twisted propeller-like conformation in the $\mathrm{SC}_{\mathrm{g}}$ polymorph, which prevented the formation of detrimental species, such as excimers or exciplexes, caused by $\pi-\pi$ stacking interactions. Furthermore, numerous intermolecular interactions such as $\mathrm{C}-\mathrm{H} \cdots \pi$ and $\mathrm{C}-\mathrm{H} \cdots \mathrm{S}$ might also exist in the crystals aside from the $\mathrm{C}-\mathrm{H} \cdots \mathrm{O}$ hydrogen bonding (Fig. $5 \mathrm{~b}$ and Table S3†). These multiple interactions had rigidified the molecular conformations and impeded intramolecular rotation, which largely reduced the energy loss via non-radiative 
relaxation channels, and subsequently resulted in a notable AIE effect and high $\Phi_{\mathrm{F}, \mathrm{s}}$ value for $\mathrm{P}_{4} \mathrm{TA}$. The preceding factors consequently made the ML of sample $\mathrm{C}_{g}$, which was mainly composed of $\mathrm{P}_{4}$ TA microcrystals in the $\mathrm{SC}_{\mathrm{g}}$ polymorph, highly emissive under the stimulus of mechanical force. By contrast, the weaker piezoelectric effect in the $\mathrm{SC}_{\mathrm{b}}$ polymorph seemed not to reach the higher energy requirement for the electronic excitation although $\mathrm{SC}_{\mathrm{b}}$ also exhibited strong photoluminescence. Consequently, $\mathrm{P}_{4}$ TA lost its ML activity when aggregated in the $\mathrm{C}_{\mathrm{b}}$ phase. These results also suggest a feasible design direction for the development of efficient ML materials through combining the prominent piezoelectric property for molecular excitation and the abnormal AIE character for emission.

The PL of $C_{b}$ was remarkably changed when the sample was exposed to DCM or acetone vapors for about $10 \mathrm{~min}$, passing from an initial blue to green light at $499 \mathrm{~nm}\left(\mathrm{C}_{\mathrm{bf}^{-}}\right.$ form). The resulting spectrum of $\mathrm{C}_{\mathrm{bf}}$ was superimposable on that of $\mathrm{C}_{\mathrm{g}}$ (Fig. 2b). The coincidence of the PL emissions suggested that the fumed sample of $\mathrm{C}_{\mathrm{bf}}$ probably had the same molecular arrangement as that of the $\mathrm{C}_{\mathrm{g}}$ polymorph. Further evidence for this standpoint was provided by their similar XRD patterns and their overlapping DSC curves with the same melting point at $206{ }^{\circ} \mathrm{C}$ (Fig. $4 \mathrm{a}$ and b). As mentioned in the preceding discussion, sample $\mathrm{C}_{\mathrm{g}}$ was MLactive. And expectantly, the ML activity of $\mathrm{C}_{\mathrm{b}}$ could be tuned by simply altering the molecular packing mode upon fumigation. To verify this hypothesis, the ML spectrum of $\mathrm{C}_{\mathrm{b}}$ was collected after exposure to DCM vapor $\left(\mathrm{C}_{\mathrm{bf}}\right)$. As anticipated, $\mathrm{C}_{\mathrm{bf}}$ also exhibited a strong green light emission without $\mathrm{UV}$ irradiation using pressure, which revealed that the $M L$ of $C_{b}$ could be facilely turned on with the aid of DCM vapor. The ML emission maximum of $\mathrm{C}_{\mathrm{bf}}$ was located at $520 \mathrm{~nm}$, which is close to that of $\mathrm{C}_{\mathrm{g}}$ (Fig. 3a).

Noticeably, the $\mathrm{ML}$ maxima of $\mathrm{C}_{\mathrm{g}}$ and $\mathrm{C}_{\mathrm{bf}}$ were both significantly red-shifted $\left(\Delta \lambda_{\mathrm{em}, \max } \approx 21 \mathrm{~nm}\right)$ as compared to their PL spectra. This result shows a special mechanofluorochromic effect. To gain an understanding of this, the influence of applied pressure on the luminescence was investigated. The PL maximum of the pristine $\mathrm{P}_{4}$ TA in the $\mathrm{C}_{\mathrm{g}}$ form shifted from $498 \mathrm{~nm}$ to $521 \mathrm{~nm}\left(\mathrm{G}_{\mathrm{g}}\right)$ after pressing or grinding (Fig. 2a), agreeing well with its ML emission (Fig. S6†), thereby confirming that the bathochromic shift between the ML and PL of $\mathrm{C}_{\mathrm{g}}$ was caused by its intrinsic mechanochromic properties. The phase characteristics of the ground sample $\mathrm{G}_{\mathrm{g}}$ were determined by XRD to decipher further the relationship between the $\mathrm{ML}$ and the mechanochromism of $\mathrm{C}_{\mathrm{g}}$. Most of the diffraction peaks were diffuse or even disappeared, although some resolvable peaks of $\mathrm{G}_{\mathrm{g}}$ were consistent with those of their original crystals (Fig. 6a). This revealed that the ground sample was partially in a metastable amorphous state. Accordingly, DSC was performed for the sample after grinding (Fig. 6b). Compared with $\mathrm{C}_{\mathrm{g}}$, an additional exothermal peak around $86{ }^{\circ} \mathrm{C}$ was observed in the DSC thermogram of $G_{g}$, which demonstrated that the $C_{g}$ crystals were partially destroyed and converted to an amorphous state by the grinding or pressing treatment. The $\mathrm{P}_{4}$ TA molecules in the $\mathrm{C}_{\mathrm{g}}$ phase adopt twisted conformations in the crystalline state to
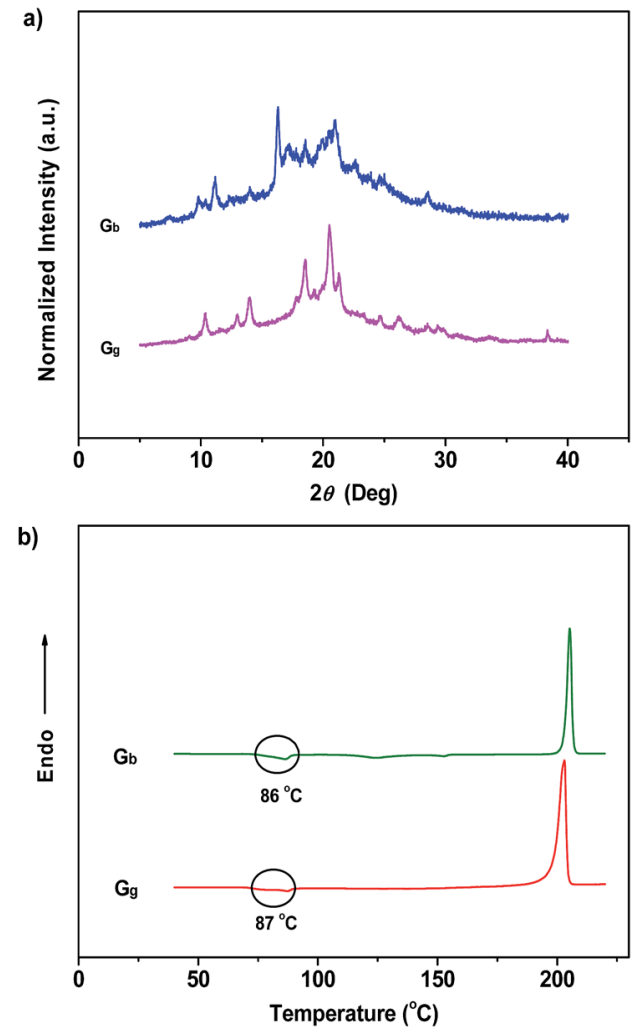

Fig. 6 XRD patterns (a) and DSC curves (b) of the ground samples of $P_{4}$ TA: $\left(G_{b}\right)$ ground sample from the blue-light crystals; $\left(G_{g}\right)$ ground sample from the green-light crystals.

fit into the crystalline lattice, and the crystalline lattices may collapse when triggered with mechanical force. The dye molecules also then relaxed to a more planar conformation, thereby emitting redder ML and PL. In other words, the bathochromic shift of the $\mathrm{ML}$ for $\mathrm{C}_{\mathrm{g}}$ originates from the microcrystal amorphization and the extension of molecular conjugation, which were believed to be the main reasons for the $\mathrm{C}_{\mathrm{g}}$ mechanochromism. ${ }^{\mathbf{1 6}, 17}$ Unlike other conventional stimuli-responsive materials, the $\mathrm{C}_{\mathrm{g}}$-form of $\mathrm{P}_{4}$ TA can show a luminescence response and luminescence color change simultaneously and respectively both without and with UV irradiation under a force stimulus. This new kind of forceresponsive material with AIE properties has not yet been achieved before, and would facilitate applications of $\mathrm{ML}$ materials in the field of sensors. ${ }^{11 c}$ In addition, fluorescence spectroscopy was also performed to evaluate the mechanochromic behavior of $\mathrm{P}_{4}$ TA in the $\mathrm{C}_{\mathrm{b}}$ phase, and the $\mathrm{C}_{\mathrm{b}}$ sample exhibited a more remarkable emission wavelength change of $47 \mathrm{~nm}$ upon grinding. Furthermore, the corresponding PL spectrum $\left(G_{b}\right)$ with $\lambda_{\text {em,max }}=523 \mathrm{~nm}$ fitted well with that for the powder ground from $\mathrm{C}_{\mathrm{g}}$ (Fig. 2b), which indicated that $\mathrm{P}_{4}$ TA could switch to the same emission under a force stimulus regardless of its initial state. Also the fluorescence 'writability' of $\mathrm{C}_{\mathrm{b}}$ can be verified by writing on a piece of filter paper as shown in Fig. 3d. The mechanofluorochromism of $\mathrm{C}_{\mathrm{b}}$ should occur by a similar mechanism to that proposed for $\mathrm{C}_{\mathrm{g}}$. 


\section{Conclusions}

Based on AIE-active $\mathrm{P}_{4}$ TA molecules, two photoluminescent polymorphs (i.e., $\mathrm{C}_{\mathrm{g}}$ and $\mathrm{C}_{\mathrm{b}}$ ) with multiple molecular conformations were achieved. They can show opposing mechanoluminescence activities by tuning the molecular assembly structures in the crystals. The block-like crystals of $\mathrm{C}_{\mathrm{g}}$ exhibited a very bright green color ML upon pressing or grinding under daylight at room temperature. This unique property should be attributed to the strong piezoelectric effect of the crystals and the positive effect of the AIE property on luminescence enhancement. Moreover, with UV irradiation, the $\mathrm{C}_{g}$ of $\mathrm{P}_{4} \mathrm{TA}$ showed mechanofluorochromism under a mechanical stimulus. This new kind of force-responsive compound with an AIE property could facilitate the application of ML materials in the display and sensor fields. This work may provide a feasible design direction for the development of more efficient $\mathrm{ML}$ materials by combining the prominent piezoelectric property for molecular excitation and the unique AIE character for emission.

\section{Acknowledgements}

The authors gratefully acknowledge financial support from the NSF of China (51173210, 51073177), the Fundamental Research Funds for the Central Universities and NSF of Guangdong (S2011020001190).

\section{Notes and references}

1 (a) N. C. Eddingsaas and K. S. Suslick, Nature, 2006, 444, 163; (b) N. C. Eddingsaas and K. S. Suslick, J. Am. Chem. Soc., 2007, 129, 6718.

2 S. M. Jeong, S. Song, K. I. Joo, J. Kim, S. H. Hwang, J. Jeong and H. Kim, Energy Environ. Sci., 2014, 7, 3338.

3 (a) S. Moon Jeong, S. Song, S. K. Lee and B. Choi, Appl. Phys. Lett., 2013, 102, 051110; (b) S. M. Jeong, S. Song, S. K. Lee and N. Y. Ha, Adv. Mater., 2013, 25, 6194; (c) D. O. Olawale, T. Dickens, W. G. Sullivan, O. I. Okoli, J. O. Sobanjo and B. Wang, J. Lumin., 2011, 131, 1407; (d) I. Sage and G. Bourhill, J. Mater. Chem., 2001, 11, 231; (e) Y. Tsuboi, T. Seto and N. Kitamura, J. Phys. Chem. B, 2003, 107, 7547.

4 (a) G. E. Hardy, J. C. Baldwin, J. I. Zink, W. C. Kaska, P. H. Liu and L. Duboisi, J. Am. Chem. Soc., 1997, 99, 3552; (b) L. M. Sweeting, A. L. Rheingold, J. M. Gingerich, A. W. Rutter, R. A. Spence, C. D. Cox and T. J. Kim, Chem. Mater., 1997, 9, 1103; (c) L. M. Sweeting, Chem. Mater., 2001, 13, 854.

5 H. Nakayama, J. I. Nishida, N. Takada, H. Sato and Y. Yamashita, Chem. Mater., 2012, 24, 671.

6 (a) G. E. Hardy, J. I. Zink, W. C. Kaska and J. C. Baldwin, J. Am. Chem. Soc., 1978, 100, 8001; (b) G. E. Hardy, W. C. Kaska, B. P. Cbandra and J. I. Zink, J. Am. Chem. Soc., 1981, 103, 1074; (c) E. Boldyreva, Chem. Soc. Rev., 2013, 42, 7719 .
7 (a) H. Y. Zhang, Z. L. Zhang, K. Q. Ye, J. Y. Zhang and Y. Wang, Adv. Mater., 2006, 18, 2369; (b) K. Wang, H. Zhang, S. Chen, G. Yang, J. Zhang, W. Tian, Z. Su and Y. Wang, Adv. Mater., 2014, 26, 6168.

8 L. M. Sweeting and A. L. Rheingoldf, J. Am. Chem. Soc., 1987, 109, 2652.

9 (a) R. Jakubiak, C. J. Collison, W. C. Wan, L. J. Rothberg and B. R. Hsieh, J. Phys. Chem. A, 1999, 103, 2394; (b) K. C. Wu, P. J. Ku, C. S. Lin, H. T. Shih, F. I. Wu, M. J. Huang, J. J. Lin, I. C. Chen and C. H. Cheng, Adv. Funct. Mater., 2008, 18, 67; (c) P. Galer, R. C. Korošec, M. Vidmar and B. Šket, J. Am. Chem. Soc., 2014, 136, 7383.

10 (a) J. Luo, Z. Xie, J. W. Y. Lam, L. Cheng, B. Z. Tang, H. Chen, C. Qiu, H. S. Kwok, X. Zhan, Y. Liu and D. Zhu, Chem.Commun., 2001, 1740; (b) B. K. An, S. K. Kwon, S. D. Jung and S. Y. Park, J. Am. Chem. Soc., 2002, 124, 14410; (c) H. Tong, Y. Hong, Y. Dong, M. Häußler, J. W. Y. Lam, Z. Li, Z. Guo, Z. Guo and B. Z. Tang, Chem. Commun., 2006, 3705; (d) W. Z. Yuan, P. Lu, S. Chen, J. W. Y. Lam, Z. Wang, Y. Liu, H. S. Kwok, Y. Ma and B. Z. Tang, Adv. Mater., 2010, 22, 2159; (e) B. Xu, M. Xie, J. He, B. Xu, Z. Chi, W. Tian, L. Jiang, F. Zhao, S. Liu, Y. Zhang, Z. Xu and J. Xu, Chem. Commun., 2012, 49, 273; (f) C. Li, T. Wu, C. Hong, G. Zhang and S. Liu, Angew. Chem., Int. Ed., 2011, 51, 455.

11 (a) Y. Hong, J. W. Y. Lam and B. Z. Tang, Chem. Commun., 2009, 4332; (b) Y. Hong, J. W. Y. Lam and B. Z. Tang, Chem. Soc. Rev., 2011, 40, 5361; (c) Z. Chi, X. Zhang, B. Xu, X. Zhou, C. Ma, Y. Zhang, S. Liu and J. Xu, Chem. Soc. Rev., 2012, 41, 3878; (d) Z. Zhao, J. W. Y. Lam and B. Z. Tang, J. Mater. Chem., 2012, 22, 23726; (e) Y. Gong, Y. Zhang, W. Z. Yuan, J. Z. Sun and Y. Zhang, J. Phys. Chem. C, 2014, 118, 10998.

12 (a) B. Xu, Z. Chi, H. Li, X. Zhang, X. Li, S. Liu, Y. Zhang and J. Xu, J. Phys. Chem. C, 2011, 115, 17574; (b) Z. Yang, W. Qin, J. W. Y. Lam, S. Chen, H. H. Y. Sung, I. D. Williams and B. Z. Tang, Chem. Sci., 2013, 4, 3725.

13 (a) J. I. Zink and W. Klimt, J. Am. Chem. Soc., 1974, 96, 4960; (b) P. Jha and B. P. Chandra, Luminescence, 2014, 29, 977.

14 (a) S. Biju, N. Gopakumar, J. C. G. Bünzli, R. Scopelliti, H. K. Kim and M. L. P. Reddy, Inorg. Chem., 2013, 52, 8750; (b) S. Balsamy, P. Natarajan, R. Vedalakshmi and S. Muralidharan, Inorg. Chem., 2014, 53, 6054.

15 L. S. McCarty and G. M. Whitesides, Angew. Chem., Int. Ed., 2008, 47, 2188.

16 R. Misra, T. Jadhav, B. Dhokale and S. M. Mobin, Chem. Commun., 2014, 50, 9076.

17 (a) W. Z. Yuan, Y. Tan, Y. Gong, P. Lu, J. W. Y. Lam, X. Y. Shen, C. Feng, H. H. Y. Sung, Y. Lu, I. D. Williams, J. Z. Sun, Y. Zhang and B. Z. Tang, Adv. Mater., 2013, 25, 2837; (b) Y. Gong, Y. Tan, J. Liu, P. Lu, C. Feng, W. Z. Yuan, Y. Lu, J. Z. Sun, G. He and Y. Zhang, Chem. Commun., 2013, 49, 4009; (c) P. Gautam, R. Maragani, S. M. Mobin and R. Misra, RSC Adv., 2014, 4, 52526. 